\title{
COST 296 scientific results designed for operational use
}

\author{
Iwona Stanislawska ( $\left(^{1}\right)$, Anna Belehaki ( $\left.{ }^{2}\right)$, Norbert Jakowski $\left({ }^{3}\right)$, Bruno Zolesi ( $\left(^{4}\right)$, \\ Tamara L. Gulyaeva $\left({ }^{5}\right)$, Ljiljana R. Cander $\left({ }^{6}\right)$, Bodo W. Reinisch $\left({ }^{7}\right)$, Michael Pezzopane $\left({ }^{4}\right)$, \\ Ioanna Tsagouri $\left({ }^{2}\right)$, Lukasz Tomasik $\left({ }^{1}\right)$ and Ivan Galkin $\left({ }^{7}\right)$ \\ (') Space Research Centre PAS, Warsaw, Poland \\ ${ }^{(2)}$ National Observatory of Athens, Athens, Greece \\ $\left(^{3}\right)$ DLR, Institute of Communications and Navigation, Neustrelitz, Germany \\ ${ }^{4}{ }^{4}$ Istituto Nazionale di Geofisica e Vulcanologia, Roma, Italy \\ (5) IZMIRAN, Troitsk, Moscow Region, Russia \\ $\left.{ }^{(}\right)$Rutherford Appleton Laboratory, Chilton, UK \\ (') Center for Atmospheric Research, UMass Lowell, USA
}

\begin{abstract}
The main objective of the COST 296 Action «Mitigation of Ionospheric Effects on Radio Systems» is the establishment/improvement of ionospheric services by coordinating the development of specific algorithms, models, and tools capable of operating in a near-real-time mode.

Key elements of these activities are contributions related to monitoring, modelling, and imaging of customer-relevant ionospheric quantities. COST stimulates, coordinates, and supports Europe's goals of development and global cooperation by providing high quality information and knowledge of ionospheric and plasmaspheric conditions enabling high quality and reliable operation of radio systems.

It also provides a platform for sharing such tools as algorithms or models, and for the joint development of advanced technologies. It takes advantage of many national and European service initiatives, for example DIAS (http://dias.space.noa.gr), SWACI (http://w3swaci.dlr.de), ESWUA (http://www.eswua.ingv.it/ingv), RWC-Warsaw (http://www.cbk.waw.pl/rwc), the COST Prompt Ionospheric Database http://www.wdc.rl.ac.uk/cgibin/digisondes/cost_database.pl, http://www.izmiran.ru/services, and others.

Existing national capabilities are taken into account to develop synergies and avoid duplication. The enhancement of environment monitoring networks and associated instrumentation yields mutual advantages for European and regional services specialized for local user needs.

It structurally increases the integration of limited-area services, and generates a platform employing the same approach to each task differing mostly in input and output data. In doing so it also provides a complementary description of the environmental state within issued information, as well as providing a platform for interaction among local end users, who define what kind of information they need, for system providers, who finalize the tools necessary to obtain required information, and for local service providers, who do the actual processing of data, tailoring it to specific users' needs. Such an initiative creates a unique opportunity for small national services to consolidate their product design so that is no longer limited to their own activity, but can serve the wider European services.

The development and improvement of techniques for mitigating ionospheric effects on radio systems by the COST 296 Action prepared those services that implemented the new design techniques for the newly announced EU and ESA policy-Space Situation Awareness (SSA). COST 296 developments applied to nowcasting and forecasting services are an essential input to the Operational SSA Ionosphere.
\end{abstract}

Mailing address: Dr. Iwona Stanislawska, Space Research Centre PAS, 00-716 Warsaw, Bartycka 18a, Poland; e.mail: stanis@cbk.waw.pl 
Key words Ionosphere monitoring - forecasting services

\section{Introduction}

The main objective of the Action COST 296 «Mitigation of Ionospheric Effects on Radio Systems», as written in the Memorandum of Understanding signed at the beginning by 15 signatory countries, is to develop increased knowledge of effects imposed by the ionosphere on operational radio systems, and for the development and implementation of techniques to mitigate the deleterious effects of the ionosphere on such systems. While the primary scientific and technical goals of the Action were the development and evaluation of ionosphere and plasmasphere models, and of algorithms leading to improved radio wave propagation simulations, the main benefit derived from the research and development undertaken within the Action will be the value- added products applicable to the current and new generation of radio systems operated in, or affected by, the near-Earth plasma environment. In this context, the best achievements are implemented in the computer programs prepared to provide support for $\mathrm{HF}$ radio-communication in accordance with the COST 296 Mission Statement. The use of currently operating services needs a number of adaptations and adjustments. Some of them are direct Action issues; others are the responsibilities of the services' owners. The Action itself proposes useful and convenient approaches, and new algorithms generate novel directions for the operational services.

This paper briefly describes some examples of applications in currently existing systems.

\section{Results and their adaptation}

- Forecasting of the ionosphere conditions, ESWUA

An example of disturbance forecasting is the ionospheric forecasting empirical local model over Rome (IFELMOR), which predicts the state of the critical frequency of the $F 2$ lay- er ( $f o F 2$ ) during strong geomagnetic storms and disturbed ionospheric conditions.

Hourly measurements of foF 2 obtained at the Rome observatory, hourly quiet-time values of $f o F 2 \quad\left(f o F 2_{\mathrm{QT}}\right)$, made available by the ESWUA system (Romano et al., 2008), and the hourly time-weighted accumulation series derived from the geomagnetic planetary index ap $(\operatorname{ap}(\tau))$, were considered during the period January 1976-December 2003. Statistically significant regression coefficients were obtained for the relation between the ionospheric disturbance index $\log \left(f o F 2 / f o F 2_{\mathrm{QT}}\right)$ and the integrated geomagnetic index ap $(\tau)$, for different months and for different ranges of $\operatorname{ap}(\tau)$ and used as input to calculate the short-term forecasting of $f_{o F}$. The IRI (Bilitza and Reinisch, 2008) empirical STORM model (AraujoPradere et al., 2002) was compared with the IFELMOR model, and the predictions were similar, particularly for periods characterized by high geomagnetic activity and very disturbed ionospheric conditions.

\section{- GIFINT (Geomagnetic Indices Forecasting and Ionospheric Nowcasting Tools)}

The GIFINT (Geomagnetic Indices Forecasting and Ionospheric Nowcasting Tools) project provides a tool for forecasting geomagnetic indices and for nowcasting ionospheric conditions over the central Mediterranean area. Results of these tools are available on http://gifint.ifsi.rm.cnr.it/.

The Simplified Ionospheric Regional Model updated in real-time, SIRMUP (Zolesi et al., 2004; Tsagouri et al., 2005), uses autoscaled ionospheric parameters observed by two AISINGV ionosondes at Rome and Gibilmanna (Pezzopane and Scotto, 2007) to perform nowcasting of the main ionospheric characteristics. The ionospheric nowcasting tool in GIFINT produces: i) real-time $f$-plots of the main ionospheric characteristics such as $f o F 2, M(3000) F 2$, $M U F(3000) F 2, f x$ I, foF 1, ftEs, and h'Es along with the electron density profile for both ionospheric stations at Rome and Gibilmanna (fig. 1); (ii) nowcasting maps of $f_{o F} 2$ and $M(3000) F 2$ over Italy and the near Balkan regions with a time resolution of one hour (fig. 2). 
Rome (lat: +41.8, lon: 012.5) - DATE: 20081016 - TIME (UT): 09:30
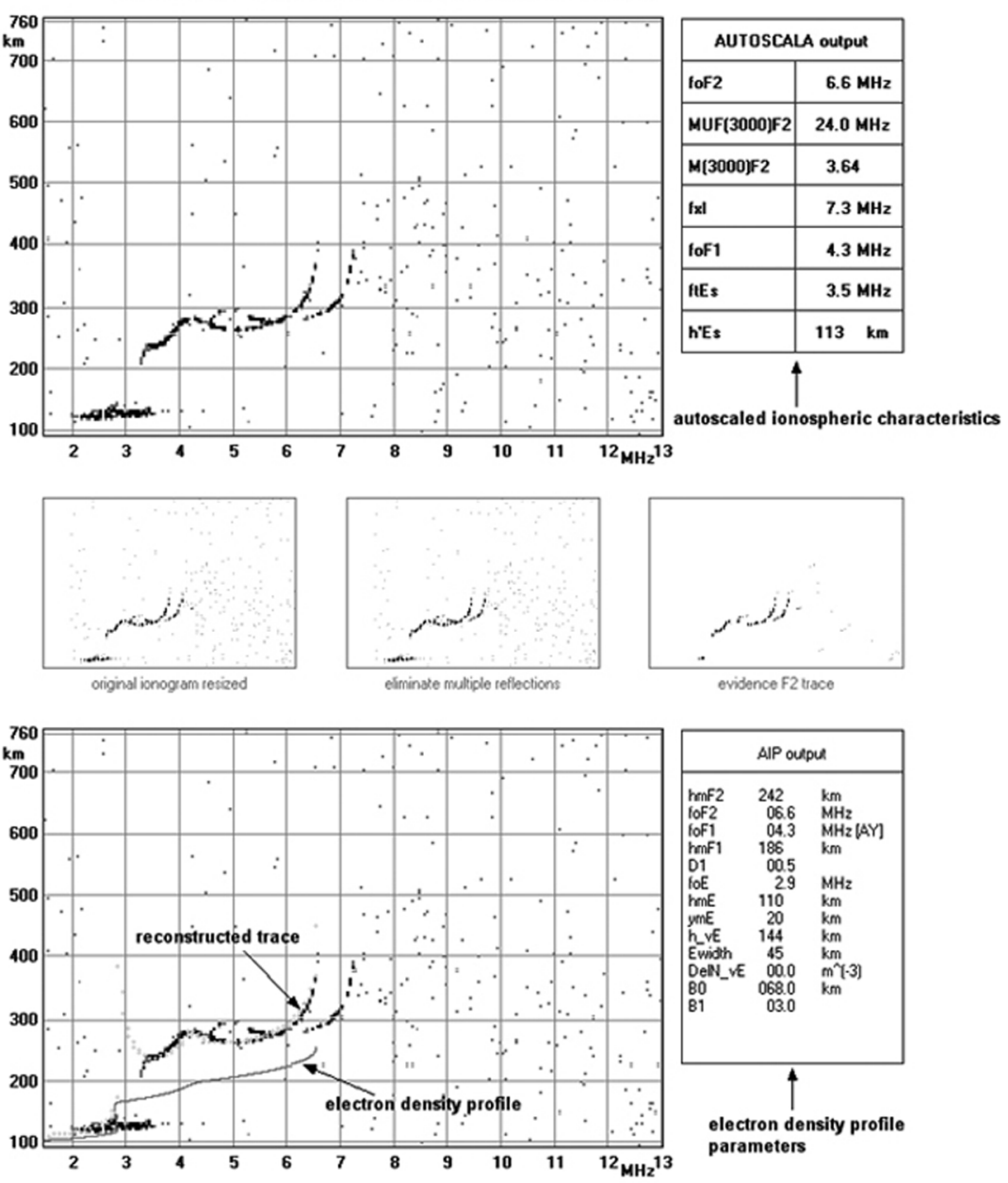

Fig. 1. Ionogram recorded at Gibilmanna by the AIS-INGV ionosonde and autoscaled by Autoscala.

- RAL on-line service for Radio Communications Users at http://ionosphere.rcru.rl.ac.uk/

RAL's Space Weather Web - Facilities for Radio Communications Users. Access to realtime information on ionospheric conditions over Europe, as a requirement for high frequency communication, satellite-to-ground links, solar-terrestrial research and space weather applications, requires:

i) A network of vertical ionosondes in- volving as wide a European participation as possible to be set up for real-time data access at http://www.wdc.rl.ac.uk/cgi-bin/digisondes/cost_database.pl;

ii) Short-term forecasting algorithms for foF2, $M(3000) F 2$, TEC, and FOT sufficiently robust to predict events up to 24 hours ahead, and even 72 hours ahead to deal with weekend problems (Zolesi and Cander, 2008 and references therein);

iii) A mapping algorithm for interpolation be- 


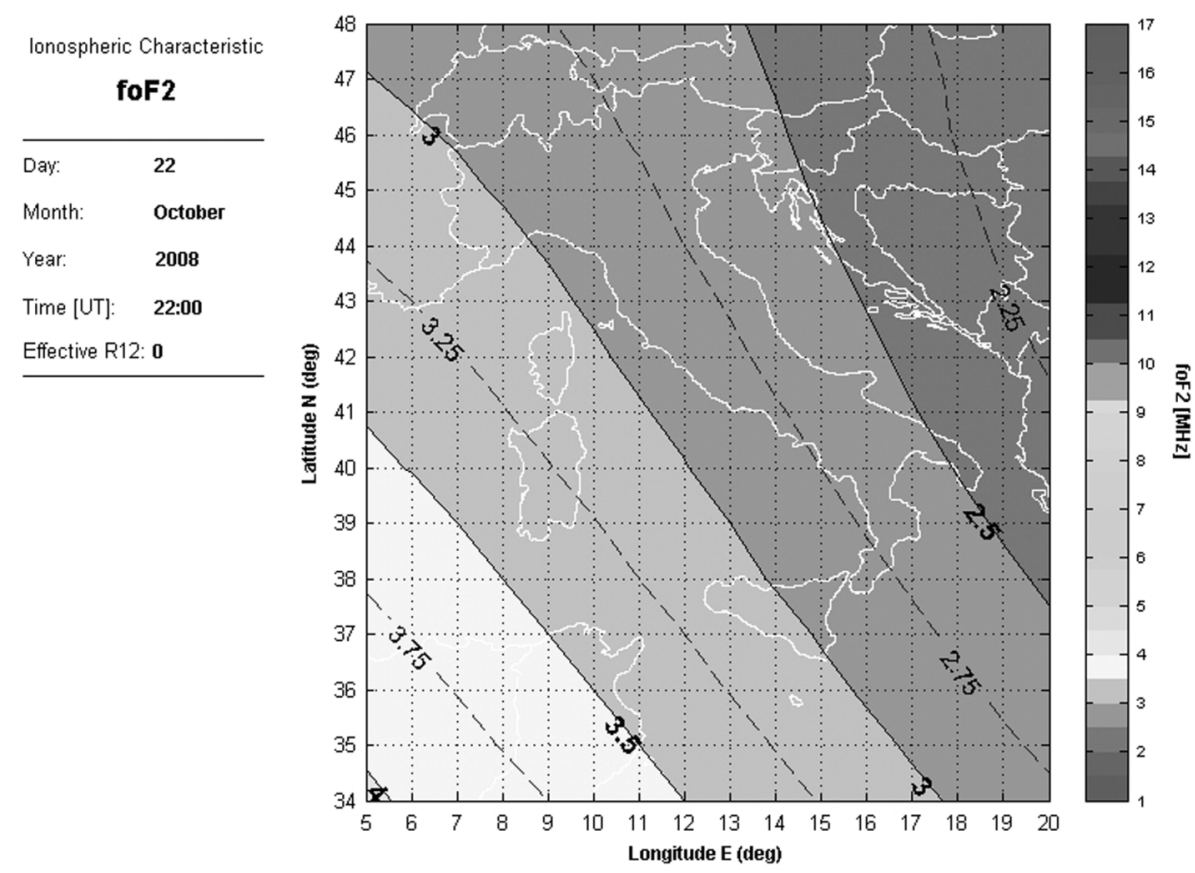

Fig. 2. Nowcasting map of foF2 obtained by SIRMUP over Italy and near Balkan region.

tween the stations in the network by using the Kriging instantaneous mapping procedure (Stanislawska and Cander, 1999 and references therein);

iv) Validation of the mapping and forecasting algorithms (Cander, 2008 and references therein).

As a response to these needs, an operational Short-Term Ionospheric Forecasting (STIF) tool for the European region has been developed http://ionosphere.rcru.rl.ac.uk/). It is designed to provide $24 / 7$ services for the forecasting for up to 24 hours ahead and for archiving measurement maps of the critical frequency $f_{o F}$, the Maximum Usable Frequency for a $3000 \mathrm{~km}$ range $M U F(3000) F 2$, the vertical Total Electron Content (TEC), and the Frequency of Optimum Traffic (FOT) for the area of interest at each UT hour. In particular: 1) interactive forecast maps of foF2, $M U F(3000) F 2$, and ITU-R NeQuick modelled TEC values over Eu- rope based on ionosonde measurements; 2) real-time dynamic system for monitoring ionospheric propagation conditions over Europe; 3) near real-time TEC maps over Europe and 24hour plots based on TEC evaluation from IGS GPS measurements; 4) real-time European TEC maps and daily vertical TEC single station plots; 5) archive of all data and images; and 6) real-time solar-terrestrial indices and warning messages so that ionospheric and trans-ionospheric propagation conditions are known to world-wide users.

- Ionospheric disturbances (http://www.izmiran.ru/services/iweather)

Routine ionosonde observations of the critical frequency foF2 and the peak height hm $F 2$ and indexing of the ionosphere disturbances for 30 ionospheric stations are provided at http://www.izmiran.ru/services/iweather. 


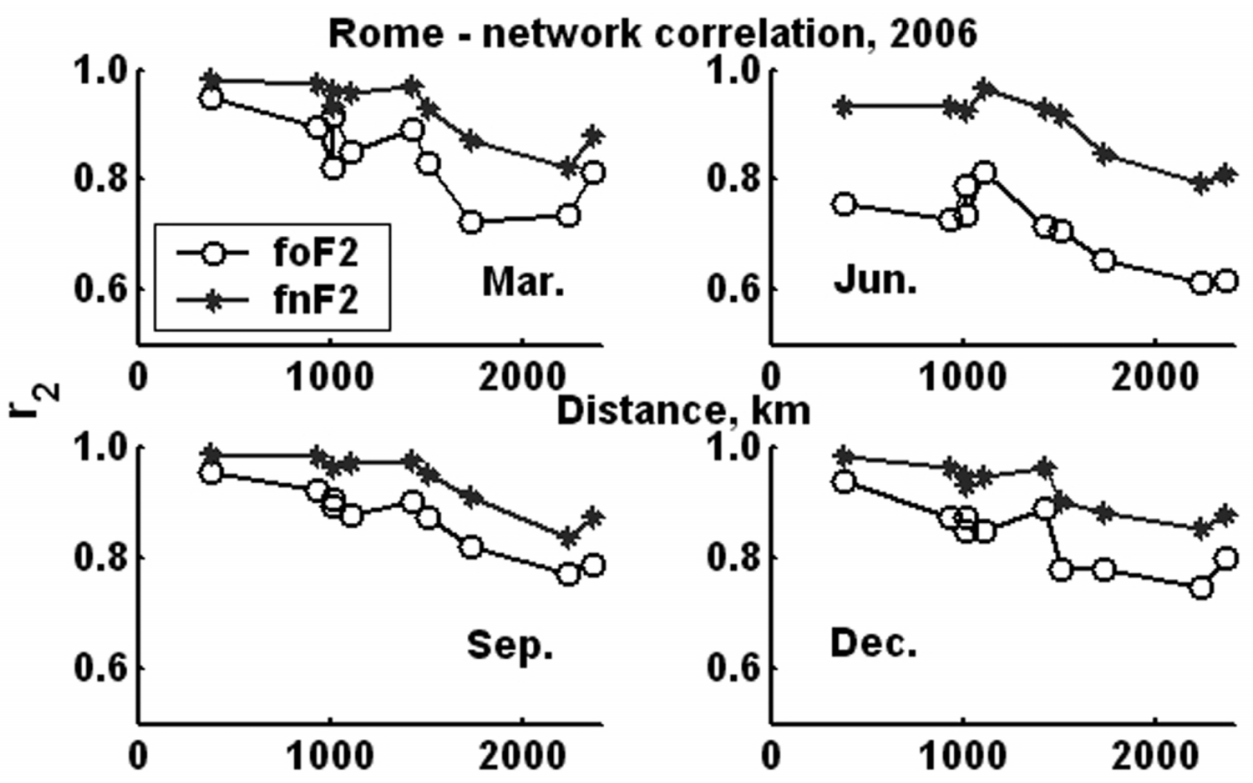

Fig. 3. Correlation coefficient for observed $f o F 2$ and $c$-transformed $f n F 2$ in terms of the distance between the stations.

Missed ionosonde observations are reconstructed by cloning data of another station (Gulyaeva et al., 2008). This process assumes proportionality of the disturbance level regarding quiet background values for parent and cloned data. The quiet reference is determined as the dailyhourly median for 27 days preceding the day of observation. The hourly variability indices $D$ and $D+$ are defined as the logarithm of the ratio of the actual hourly value of $N m F 2$ (deduced from $f_{o F}$ ) to the quiet-day reference. A segmented logarithmic scale of the ionosphere state is introduced with dynamic boundaries equal to 1 or -1 for the quiet state, 2 or -2 for moderate disturbance, 3 or -3 for a moderate ionospheric storm, and 4 or -4 for an intense ionospheric storm. The catalogue of the ionospheric disturbances of at least $3 \mathrm{~h}$ duration is mirrored at IDCE \& IZMIRAN web sites, complementing other ionospheric servers worldwide.

A technique is developed to remove the effects of the relative changes in the Sun's zenith angle $\chi$ for a particular local time and the local noon value $\chi_{0}$ on the peak electron density (Gulyaeva, 2008). An example of the resulting improvement of the inter-stations correlation is presented in fig. 3. Here the correlation coefficient for the monthly sets of foF 2 observed during four seasons at solar minimum, 2006, at Rome with the data of 10 other stations in $\mathrm{Eu}-$ rope and Russia is compared with the proxy results, $f n F 2$, reduced by the solar zenith angle. Both curves are plotted in terms of the distance between the stations given in table I.

Particularly quiet ionospheric weather conditions have been left for the analysis of fig. 3, excluding periods of the TEC-based planetary ionospheric storm index $\mathrm{Wp} \geq 4.0$ i.u. (index units) provided at the above IZMIRAN web site (Gulyaeva and Stanislawska, 2008). The improved inter-stations and inter-seasonal correlation of the proxy $f n F 2$ after the $\chi$-transform of $f o F 2$ is an indication of the presence of a more common level of quietness recorded at each pair of stations. 
Table I. Geodetic coordinates and the distance between Rome and other stations used for the correlation study.

\begin{tabular}{cccc}
\hline \hline Station & Latitude & Longitude & Distance \\
\hline Rome & 41.8 & 012.5 & $0 \mathrm{~km}$ \\
San Vito & 40.6 & 012.5 & 376 \\
Pruhonice & 50.0 & 014.6 & 926 \\
Tortosa & 40.4 & 000.3 & 1008 \\
Athens & 38.4 & 023.6 & 1016 \\
Dourbes & 50.1 & 004.6 & 1105 \\
Juliusruh & 54.6 & 013.4 & 1425 \\
Chilton & 51.6 & 358.7 & 1510 \\
El Arenosillo & 37.1 & 353.3 & 1725 \\
Rostov & 47.2 & 039.7 & 2226 \\
Moscow & 55.5 & 037.3 & 2352 \\
\hline
\end{tabular}

- Forecasting of the ionosphere conditions, $R W C$ Warsaw (http://www.cbk.waw.pl/rwc)

Forecasting of the ionosphere conditions by means of the developed « $K$ Nearest Neighbour $\mathrm{NN}$ algorithm» was placed in operation at the RWC Warsaw. The nearest neighbour method is a case-based statistical approach used to predict the ionospheric conditions.

This algorithm belongs to the group of deduction methods by analogy. The purpose of this algorithm is to classify a new forecast based on attributes and training samples. The classifiers do not use any model to fit to but are based on memorized data only.

Given a query point, the algorithm finds $K$ values closest to the query point.

The classification is done by means of using majority vote among the classification of the $K$ objects.

The $K$ Nearest Neighbour algorithm used neighbourhood classification as the prediction value for the new query instance. Figures 4 and 5 present samples from the RWC Warsaw webpage.
- TEC nowcasting, SWACI
(http://w3swaci.dlr.de)

Mitigation techniques with emphasis on ionospheric structures, their physical nature and impact on GNSS signals improved accuracy of GNSS by better ionospheric correction and errors due to ionospheric perturbations.

The Space Weather Application CenterIonosphere (SWACI) is a pilot research project of the German Aerospace Center (DLR) for establishing a space weather service primarily focused on ionospheric issues. It is well known that ground and space based GNSS measurements offer a unique chance for permanently monitoring the electron density structure of the ionosphere-plasmasphere system. Since the ionospheric impact can degrade the performance of a variety of communication and navigation radio systems, monitoring, modelling and forecasting of ionospheric perturbation processes is an important and challenging task.

Dual frequency signals of Global Navigation Satellite Systems (GNSS) measure of the integral of the electron density (TEC) along the 
M(3000)F2 in Europe 2004-05-02 12UT

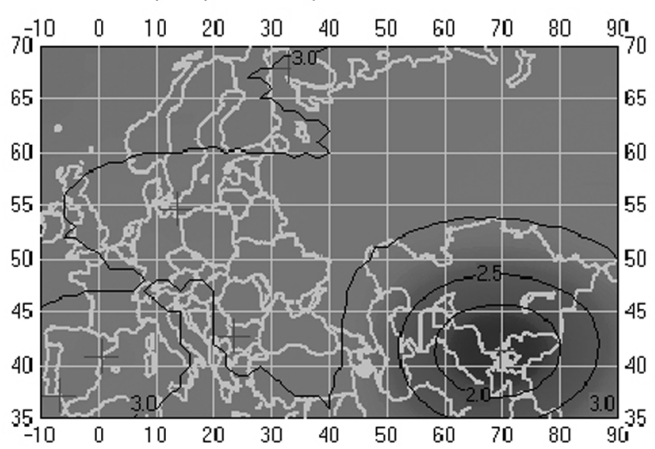

FoF2 in Europe 2004-05-02 12UT

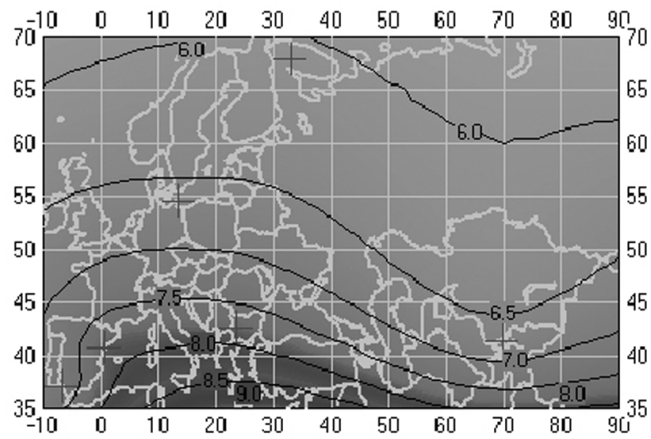

Fig. 4. Sample of $f_{o} F 2$ and $\mathrm{M}(3000) F 2$ forecasted maps for European area.

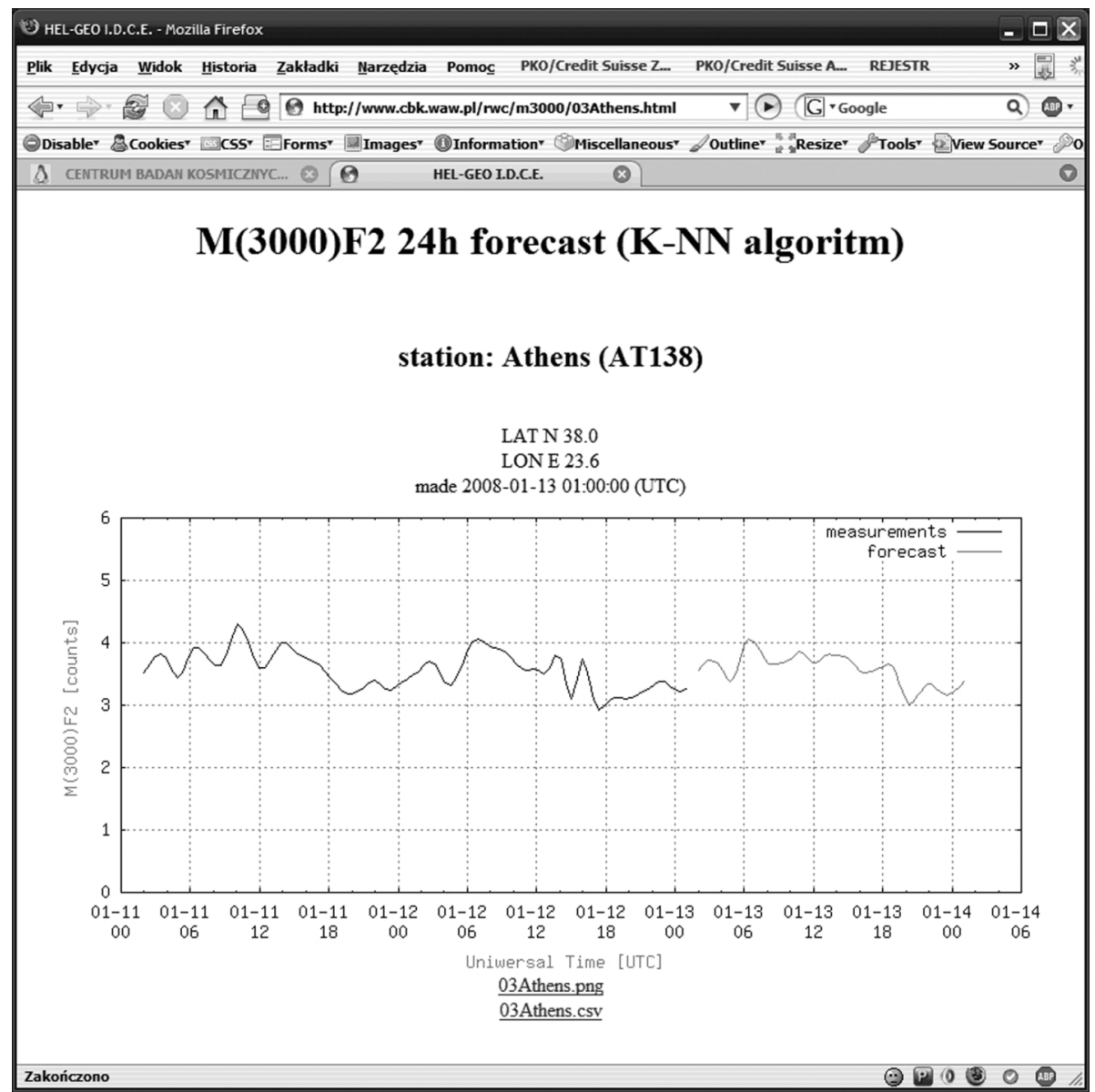

Fig. 5. Sample of $\mathrm{M}(3000) F 2$ forecasted service (http://www.cbk.waw.pl/rwc/m3000/prog.html). 


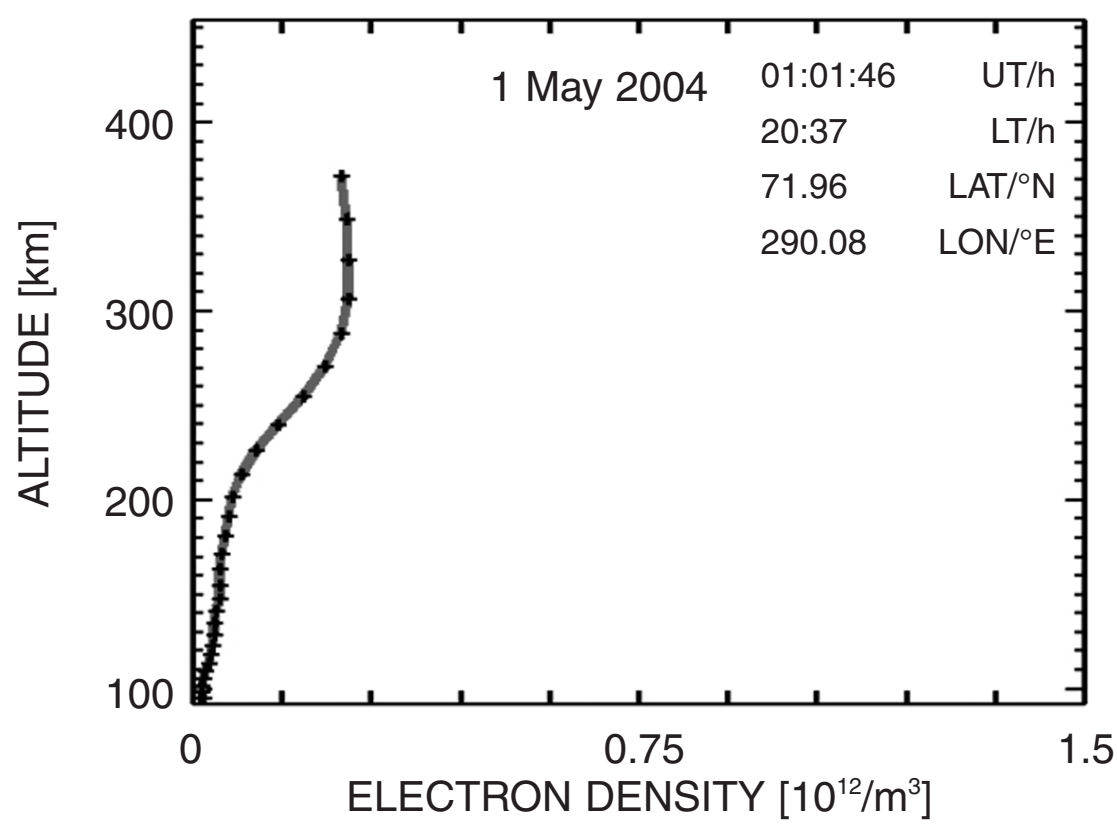

Fig. 6. Electron density profile retrieved from CHAMP IRO measurements on 1 May 2004 at high latitudes.

ray path between the transmitting GNSS satellite and the receiver, which may be installed on the Earth surface or onboard a satellite.

Ground-based TEC estimations mainly using data from the European GPS ground network of the International GNSS Service (IGS) have been carried out in DLR Neustrelitz since 1995 (Jakowski, 1996).

To create TEC maps over Europe or the North Pole area, the calibrated TEC data are assimilated into the corresponding regional TEC model NTCM-EU or NTCM-NP (http://www.kn.nz.dlr.de/daily/).

Within the operational SWACI service 1s GPS data from European GPS networks are obtained via the Federal Agency of Cartography and Geodesy of Germany (BKG Frankfurt) in streaming mode.

These data are immediately processed to generate TEC maps in near real time with an update rate of 5 minutes and a grid resolution of $1 \mathrm{x} 1 \mathrm{deg}$ in latitude and longitude, respectively (Jakowski et al., 2004).
Space-based GNSS measurements onboard the Geo-Research-Satellite CHAMP are used for reconstructing the electron density distribution in the Earth's ionosphere/plasmasphere system utilizing the ionospheric radio occultation (IRO) technique (Jakowski et al., 2002). More than 300000 vertical electron density profiles originating from the entire globe have been obtained so far (cf. fig. 6).

To facilitate the topside electron density reconstruction, and to advance the knowledge of the processes in the topside ionosphere region in general, a new method of retrieving the topside ionospheric scale height based on IRO observations onboard low-earth-orbiting (LEO) satellites has been developed (Stankov and Jakowski, 2006).

Whereas GNSS radio occultation measurements onboard an LEO satellite may provide up to about 200 vertical electron density profiles per day, topside tracking data for satellite positioning can effectively be used to monitor the 3D electron density distribution of the topside 


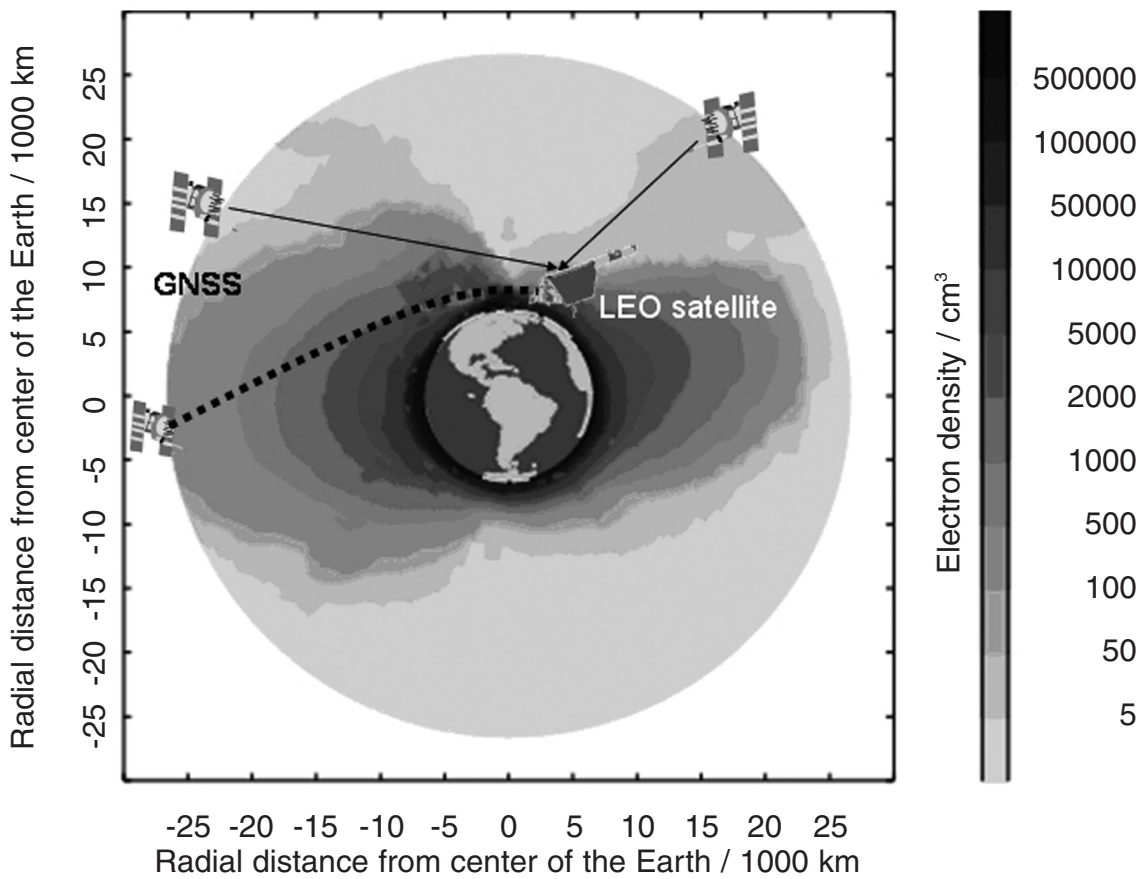

Fig. 7. Sample of topside electron density reconstruction using $0.1 \mathrm{~Hz}$ sampled navigation data measured onboard CHAMP. The figure illustrates radio links for radio occultation and topside GNSS measurements.

ionosphere/plasmasphere near the orbit plane.

For reconstructing the spatial electron density distribution near the orbit plane of the CHAMP satellite starting at about $450 \mathrm{~km}$ up to the GPS satellite altitude of about $20000 \mathrm{~km}$, an effective data assimilation technique has been applied to merge the $0.1 \mathrm{~Hz}$ sampled CHAMP navigation tracking data into the PIM ionospheric model (Heise et al., 2002). The topside reconstructions, routinely updated after each satellite revolution every $90 \mathrm{~min}$, enable routine monitoring of the Geo-plasma environment (cf. fig. 7).

\section{- SIRMUP (Real-time updating of the Simpli- fied Ionospheric Regional Model)}

SIRMUP is a simplified approach for realtime mapping of the key ionospheric characteristics foF2 and $\mathrm{M}(3000) F 2$ currently in use for prediction of the operational parameters of telecommunication systems in a restricted area of Europe $\left(5^{\circ} \mathrm{W}-40^{\circ} \mathrm{E} ; 34^{\circ} \mathrm{N}-60^{\circ} \mathrm{N}\right)$ (http://www.iono.noa.gr/DIAS) (Belehaki et al., 2006). It is based on the Simplified Ionospheric Regional Model (SIRM), a long-term prediction model, updated with real-time ionospheric observations to produce now-casting maps over Europe (Zolesi et al., 2004). SIRMUP ingests real-time automatically scaled $f_{o F}$ and $\mathrm{M}(3000) F 2$ data from ionosondes to generate the driving parameter of the SIRM, namely a regional effective sunspot number R12eff. The regional R12eff is chosen to give the best fit between the SIRM model output and the actual observations obtained from the ionosondes located in the mapping area (fig. 8). The SIRMUP simulation results, in terms of both foF 2 and $\mathrm{M}(3000) F 2$ ionospheric characteristics, carried out for various quiet and disturbed conditions, have shown a high degree of efficiency in realtime mapping of the ionospheric propagation conditions over Europe (Tsagouri et al., 2005). 


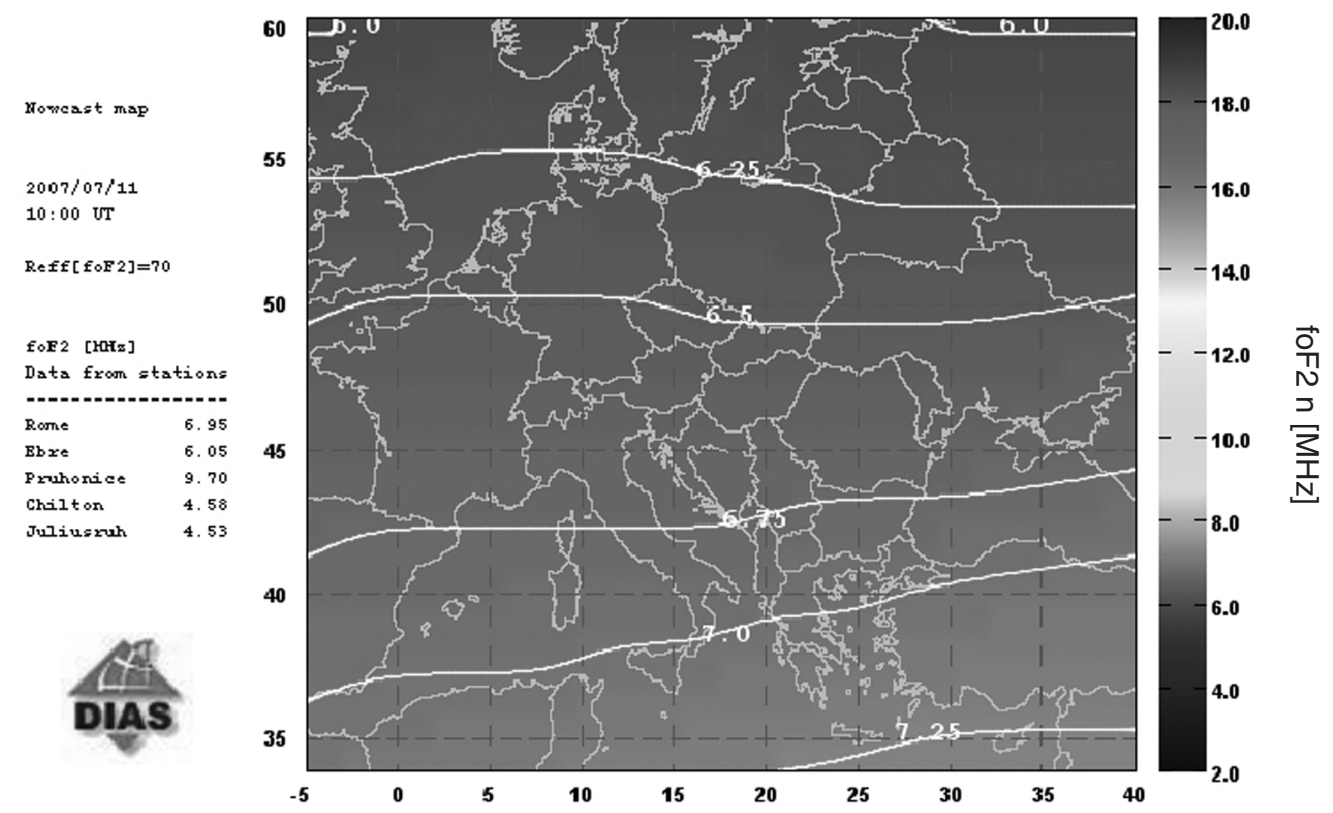

Fig. 8. Map of $f o F 2$ produced by SIRMUP and regional R12eff in the DIAS system on 11 July 2007 at 10 UT.

- Quality control of ionosonde data forDIAS services (http://dias.space.noa.gr)

A formidable challenge for the real-time model updating techniques is to guarantee acceptable quality of the automatically scaled ionospheric characteristics streaming from multiple ionosonde locations in Europe. Errors of intelligent software systems that interpret acquired ionogram images to derive ionospheric characteristics can potentially prevent the model from evolving into a selfconsistent solution that matches it with all available sensor data. Inability to obtain a solution because of an autoscaling error at one location is a far more unfavourable outcome than simply missing sensor data at one location. It is therefore beneficial to establish a quality control system for DIAS that employs techniques for real-time validation and characterization of the ionogram interpretations by intelligent autoscaling systems.

The new version 5 of the ionogram autoscaling software ARTIST for Digisonde ionograms (Galkin et al., 2008) has the capability of providing the ARTIST Confidence Level (ACL) that can be used to suppress the transmission of data to DIAS if their confidence score is too low. The ARTIST confidence score is calculated using unique internal expert system information to characterize the success of individual interpretation steps. Figure 7 shows ARTIST-5 results obtained for four days of March 2008 at Pruhonice, Czech Republic. Three ionospheric characteristics are shown: $f o F 2$ (critical frequency of the $F 2$ layer), $f_{o} F 2 p$ (predicted $f_{o} F 2$ values from the IRI model), and $h m F 2$ (height of the $F 2$ peak). The top panel presents the unfiltered set of the ARTIST results, while the bottom panel contains data with the confidence score of 41 points or better (confidence scores range from 0 to 100). Use of the ACL flag to suppress low autoscaling confidence data clearly helps to eliminate autoscaling mistakes like the ones marked by arrows in the top panel of fig. 9 .

The important aspect of such a «filtering by $A C L »$ procedure is that the confidence analysis is not based on restricting the variability of an ionospheric characteristic from ionogram to ionogram. Retrospective «smoothing» could al- 

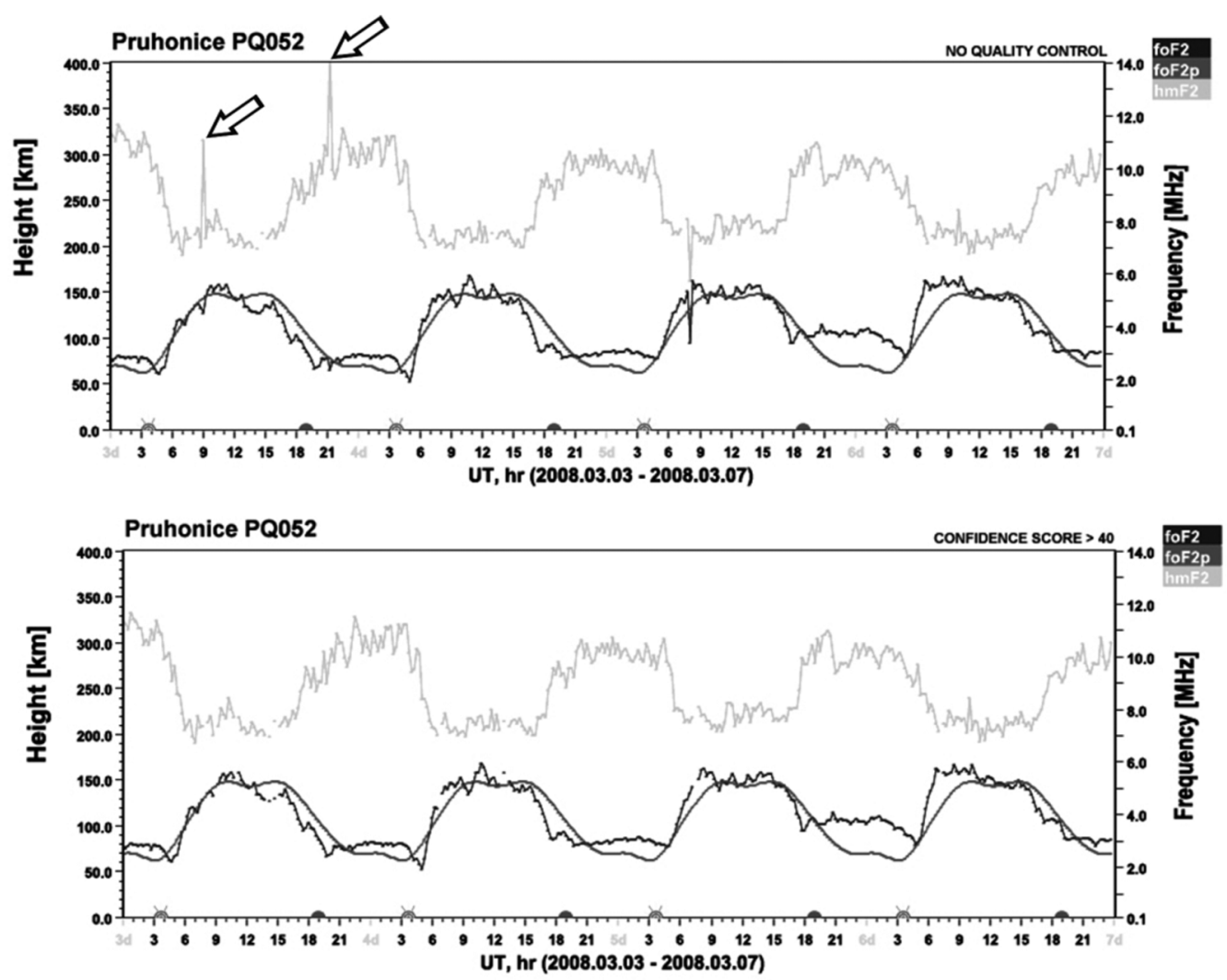

Fig. 9. ARTIST-5 autoscaling results of Pruhonice Digisonde data for 3-7 March 2008.

so suppress the outliers in fig. 9, but in a real time scenario the future data are not available. Also, restricting the variability of the characteristics would limit the ability of the ionosonde network to detect sudden changes in the ionosphere during periods of geophysical activity beyond the «synoptic» behaviour. Filtering by ACL will preserve such changes as long as the ionograms are scaled confidently. ARTIST-5 version 5.0.02 has been installed in the DPS-4 at Pruhonice and the DPS-4D (Reinisch et al., 2008) at Nicosia for trial testing.

Top panel: complete set of data without quality control, bottom panel: suppression of low confidence data from assimilation in ionospheric models. The arrows mark apparent scaling errors that are removed by quality control.
- TSAR-foF2 (Time Series AutoRegressing Models) (http://dias.space.noa.gr)

The TSAR model (Koutroumbas et al., 2008) is designed to deliver short-term forecasts (from 15 min up to 24 hours) of the foF 2 parameter at middle latitudes, based on its current and recent past values using autoregressive $(A R)$ modelling. According to evaluation results, the TSAR method provides very successful results for predictions $15 \mathrm{~min}$ and $1 \mathrm{~h}$ ahead and statistically reliable results for predictions up to 24 hours ahead. This makes TSAR a powerful tool for interpolation purposes towards the development of reliable near real-time products and services of ionospheric specification, as well as a robust forecasting technique for the delivery of reliable 


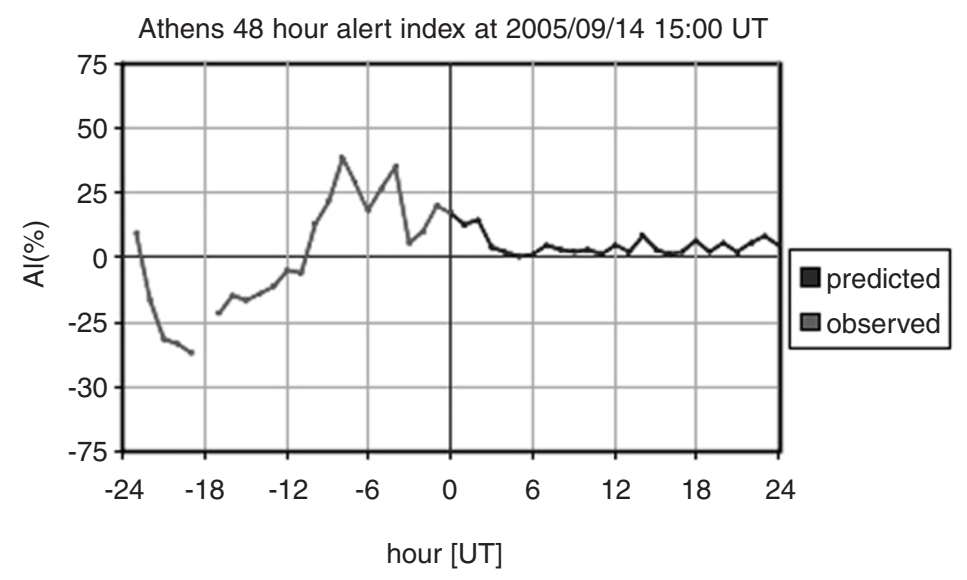

Low: lower than $25 \%$ and higher than $-25 \%$

Disturbed: between $-50 \%$ and $-25 \%$ or between $25 \%$ and $50 \%$

Extremely Disturbed: higher than $50 \%$ or lower than $-50 \%$

Fig. 10. Predicted and observed near-real time warning index (After DIAS Demo CD).

forecasts for the middle latitude ionosphere.

TSAR has been implemented online to work with real-time data in the DIAS system (http://dias.space.noa.gr) and provides ionospheric forecasts over single locations for all DIAS locations.

- Near real-time ionospheric warning index at DIAS service (http://dias.space.noa.gr)

An ionospheric alert index for the real-time monitoring of ionospheric propagation conditions over Europe and for customers' warning purposes was developed for foF 2 and $\mathrm{M}(3000) F 2$ characteristics (Bremer et al., 2006) and implemented in the DIAS system (http://dias.space.noa.gr). By using the ionospheric activity indices for several stations the ionospheric disturbance level over a substantial part of Europe $\left(5^{\circ} \mathrm{W}-40^{\circ} \mathrm{E} ; 34^{\circ} \mathrm{N}-60^{\circ} \mathrm{N}\right)$ is also displayed online in a real time alert map.

\section{Conclusions}

Knowledge of current and predicted ionospheric conditions and their possibly threatening effects on space systems enables decision-makers, planners, and operators to gain, mitigate, and maintain space superiority across the spectrum of conflict or disaster scenarios. The mitigation techniques developed and improved by the COST 296 Action and implemented in users' services prepare these services to better comply with the newly announced EU and ESA policy-Space Situation Awareness (SSA) (the Council of the European Union among others highlights the need to develop a capacity to meet European user needs for comprehensive situational awareness of the space environment through coordinated activity within Europe, and possibly with other partners). For efficient SSA it is necessary to determine the ionospheric conditions which significantly affectING the space system performance and their impact on the total ability of the warfighter.

Ground-based systems, such as surveillance or space debris tracking radars which are components of space control or satellite communication links, are all affected by their environmental conditions. The operational SSA ionospheric services have to protect and mitigate those systems. They must include:

- Monitoring and characterization of the 
ionospheric parameters relevant to space related system operation,

- Access to actual ionospheric information that allows an operational response to mitigate the space effect on the system involved,

- Assessment and prediction of the effects on space systems of man-made modification of the ionospheric conditions (electromagnetically or by nuclear detonation, plasma releases),

- Evaluation of selected ionospheric factors (such as scintillations, refraction, propagation delay) for Positioning-aided Accuracy.

COST 296 developments applied to nowcasting and forecasting services constitute a substantial input to the Operational SSA Ionosphere, providing critical inputs for the preparation of the European Space Programme, as is required by the MoU.

\section{REFERENCES}

Araujo-Pradere, E.A., T.J. Fuller-Rowell and M.V. CoDRESCU (2002): Storm: An empirical storm-time ionospheric correction model. I, Model Description, Radio Sci., 37, doi:10.1029/2001RS002467.

Belehaki, A., L.R. Cander, B. Zolesi, J. Bremer, C. JuREN, I. Stanislawska, D. Dialetis and M. HatzopouLOS (2006): Monitoring and Forecasting the Ionosphere Over Europe: The DIAS Project, Space Weather, 4, S12002, doi:10.1029/2006SW000270.

BilitZA, D. and B. REINISCH (2008): International Reference Ionosphere 2007: Improvements and new parameters, J. Adv. Space Res., 42 (4), 599-609, doi:10.1016/j.asr.2007.07.048.

Bremer, J., L.R. CANDER, J. Mielich and R. Stamper (2006): Derivation and test of ionospheric activity indices from real-time ionosonde observations in the $\mathrm{Eu}-$ ropean region, J. Atmos. Solar-Terr. Phys., 68 (18), 2075-2090.

CANDER, L.R. (2008): Ionospheric research and space weather services, J. Atmos. Solar-Terr. Phys., doi:10.1016/j.jastp.2008.05.010.

Galkin, I.A., G.M. Khmyrov, A.V. Kozlov, B.W. Reinisch, X. Huang and V.V. PAznukhov (2008): The ARTIST 5, in Radio Sounding and Plasma Physics, AIP Conf. Proc. 974, 150-159.

Gulyaeva, T.L., I. StanislawsKa and M. TOMASIK (2008): Ionospheric weather: Cloning missed foF 2 observations for derivation of variability index, Ann. Geophysicae, 26, 315-321.
Gulyaeva, T.L. and I. Stanislawska (2008): Derivation of a planetary ionospheric storm index, Ann. Geophysicae, 26, 2645-2648.

GulyaEVA, T.L. (2009): Proxy for the ionospheric peak plasma density reduced by the solar zenith angle, Earth, Planets and Space, 61, 629-631.

Jakowski, N., S.M. StanKov, D. KLAehn, Y. Beniguel and J. RUEFFER (2004): Operational service for monitoring and evaluating the space weather impact on precise positioning applications of GNSS, in Proc. European Navigation Conference ENC-GNSS2004, (17-19 May 2004, Rotterdam, The Netherlands), Paper No. GNSS2004-119.

Heise, S., N. Jakowski, A. Wehrenpfennig, Ch. Reigber and H. LÜKR (2002): Sounding of the Topside Ionosphere/Plasmasphere Based on GPS Measurements from CHAMP: Initial Results, Geophysical Research Letters, 29 (14), doi:10.1029/2002GL014738.

Koutroumbas, K., I. Tsagouri and A. BelehaKi (2008): Time series autoregression technique implemented online in DIAS system for ionospheric forecast over $\mathrm{Eu}-$ rope, Ann. Geophysicae, 36 (2), 371-386.

Pezzopane, M. and C. ScotTo (2007): The automatic scaling of critical frequency foF 2 and MUF(3000)F2: a comparison between Autoscala and ARTIST 4.5 on Rome data, Radio Sci., 42, RS4003, doi:10.1029/2006RS003581.

Reinisch, B.W., I.A. Galkin, G.M. Khmyrov, A.V. KoZlov, I.A. Lisysyan, K. Bibl, G. Cheney, D. KitrosseR, S. Stelmash, K. Roche, Y. Luo, V.V. PAaznukhov and R. HAMEL (2008): Advancing digisonde technology: the DPS-4D, in Radio Sounding and Plasma Physics, AIP Conf. Proc., 974, 127-143.

Romano, V., S. Pau, M. Pezzopane, E. Zuccheretti, B. Zolesi, G. De Franceschi and S. Locatelli (2008): The electronic Space Weather upper atmosphere (eSWua) project at INGV: advancements and state of the art, Ann. Geophysicae, 26, 345-351.

StanislawsKa, I. and L.R. CANDER (1999): Coordinated SRC and RAL Centres for ionospheric weather specification and forecasting, ESA Workshop on Space Weather, 11-13 November 1998, ESTEC, Noordwijk, The Netherlands, WPP-155, 499-552, March 1999.

STANKOV, S.M., and N. JAKOWSKI (2008): Topside ionospheric scale height analysis and modelling based on radio occultation measurements, J. Atmos. Sol.-Terr. Phys., 68 (2), 134-162.

TSAGOURI, I., B. ZOLESI, A. BELEHAKI and L.R. CANDER (2005): Evaluation of the performance of the real-time updated simplified ionospheric regional model for the European area, J. Atmos. and Sol.-Terr. Phys., 67 (12), 1137-1146.

Zolesi, B., A. Belehaki, I. Tsagouri and L.R. Cander (2004): Real-time updating of the Simplified Ionospheric Regional Model for operational applications, $R a$ dio Sci., 39 (2), RS2011, doi:10.1029/2003RS002936.

ZOLESI, B. and L.R. CANDER (2008): From COST 238 to COST 296: Four European COST Actions on Ionospheric Physics and Radio Propagation, in Radio Sounding and Plasma Physics, AIP Conf. Proc., 974, 39-46. 